\title{
Dynamics effects on a wooden footbridge
}

\author{
Veronika Vašková ${ }^{1, *}$, Lenka Poništová ${ }^{1}$ and Roman Fojtík ${ }^{1}$ \\ ${ }^{1}$ VŠB-TU Ostrava, Department of Civil Engineering, Ludvíka Podéště 1875/17, 70833 Ostrava- \\ Poruba, Czech Republic
}

\begin{abstract}
The timber is the current trend for the construction of many footbridges because of many reasons as price, aesthetics and ecology. Most of these structures are designed using simple static models and massive elements. However, there are implemented more complicated constructions including suspended footbridge in Př́bor in Czech Republic. This construction with efficient use of material is more susceptible to dynamic effect. The article describes monitoring of dynamics effects at the construction with result of installation dynamics dampers.
\end{abstract}

\section{Introduction}

The bridge construction put into service must meet the criteria both in terms of load carrying capacity but also in terms of usability perspective, which includes vibration limits on the structure. Exceeding these limits may lead to reduced mobility (comfort) of people on the construction caused by concerns of pedestrian while passing through construction. In addition, the dynamics effects may also lead to a significant damage of the structure. Especially the excessive vibrations may cause damages on the construction and destruction of a part or the whole construction. Adverse influence of vibrations can cause a substantial reduction of lifetime of the structure or its part due to cyclic fatigue.

These negative impacts are necessary to be removed or suppressed to the values that ensure safe operation of the structure and prescribed comfort, as well. It is necessary to perform the prescribed dynamic tests because of order purpose of appropriate measures and determining the status of the dynamic characteristics.

The footbridge (see Fig.1), located in Příbor in Czech Republic was designed as a subtle structure, which implies a high risk of experiencing negative dynamic impacts. Because of this, the designers of this construction prescribed dynamic load test, which had to confirm or disprove the need to use vibration dampers or determine the values that will serve for tune this damper.

\footnotetext{
* Corresponding author: veronika.vaskova.st@,vsb.cz
} 


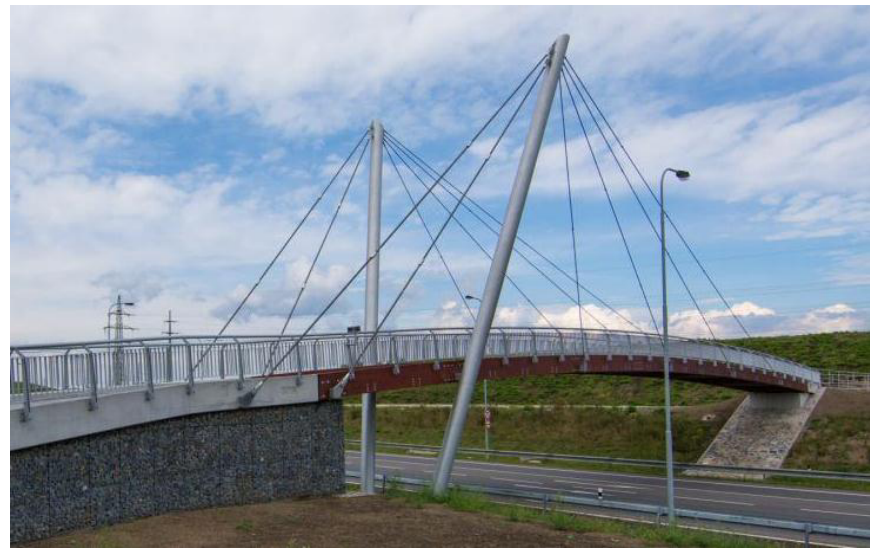

Fig. 1. A timber footbridge in Př́bor in Czech Republic.

\section{Description of construction}

The subject of this article is the cable-stayed footbridge with a length of $43 \mathrm{~m}$ and a total width of $3.44 \mathrm{~m}$. This is a direct construction with curved overhanging. The suspension is realized by using twelve steel bar rods with diameters of $28 \mathrm{~mm}$ and $45 \mathrm{~mm}$. The rods are anchored to the steel pylons with diameter of $457 \mathrm{~mm}$. Rods and pylons are made of steel S355.

The main structure (see Fig.2) consists of two main beams, which are made from glued laminated timber grade GL $28 \mathrm{~h}$ with the dimensions $220 \times 700 \mathrm{~mm}$. On the main beams, there are placed crossbeams of glued laminated timber grade GL24h and also steel crossbeams grade S355. Timber and steel crossbeams have the dimensions of $200 \times 240 \mathrm{~mm}$. On the crossbeams, there are placed three longitudinal beams of glued laminated timber grade GL24h with cross section of $120 \times 160 \mathrm{~mm}$. The footbridge pavement is made of solid oak timber grade D35. There is bracing solidification below the bridge, made of steel rods grade S355 with diameter of $18 \mathrm{~mm}$.

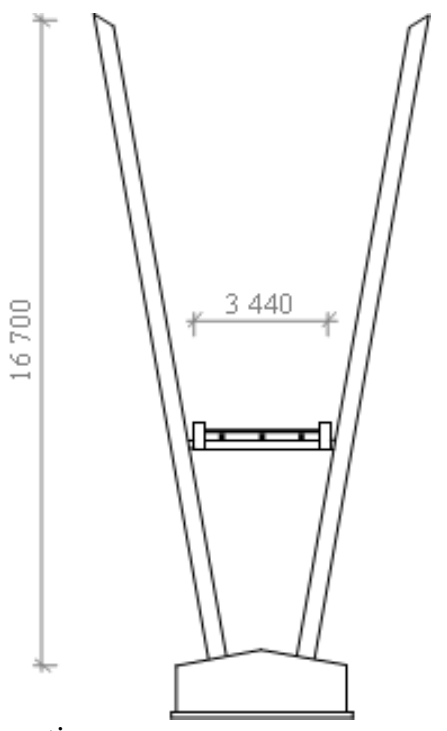

Fig. 2. Cross section of construction. 


\section{Dynamic load tests}

On the monitored footbridge there was performed a dynamic loading test to ensure that comfort of users will not be influenced during normal operation. This test was performed according to ČSN 73 6209. For deducing the dynamic effects at the footbridge, movement of one person and then movement of group of persons were used.

These load models were applied for loading by one person moving in one lane through:

- walk with frequency of about $1 \mathrm{~Hz}$;

- walk with frequency of about $2 \mathrm{~Hz}$;

- trot;

- run.

These load models were applied for loading by group of persons moving side by side in the through lane:

- walk with frequency of about $1 \mathrm{~Hz}$;

- walk with frequency of about $2 \mathrm{~Hz}$;

- trot;

- run;

- demonstrating response in the middle of the span of the footbridge

- demonstrating response in one third of the span.

The load models realized by using the walk, trot and run were always performed in both directions to ensure the relevance of results. The speed of the people movement was chosen per the adverse condition according to the standard CSN 73 6209. The aim of the test was to demonstrate the maximum acceleration amplitudes for the verification of reduced comfort of pedestrians.

\subsection{Load tests weather conditions}

All parameters of the weather conditions were measured at the beginning and at the end of the dynamic loading tests. There have been no major fluctuations in the weather conditions during measurement. The average air temperature has been measured $20.5^{\circ} \mathrm{C}$. The average wind speed varied from 0 to $1.8 \mathrm{~m} / \mathrm{s}$. Direction of the wind was South-to-Southwest.

\subsection{Used devices}

The temperature was recorded by optical thermometer. Wind speed was obtained using manual anemometer.

For dynamical measurements the seismic acceleration sensors KB12VD were used. This sensor works on the piezoelectric principle. These sensors have a great dynamical and frequency range and they do not contain the moving parts, which could cause inaccuracy of measurement.

Parameters of sensor:

- sensitivity:

- measuring range: $\quad \pm 0.6 \mathrm{~g}$

- the resonant frequency $>0.35 \mathrm{kHz}$ 
The record was conducted by using the control panel Spider 8 with sampling rate 100 $\mathrm{Hz}$ to obtain the desired values. The sensors (see Fig. 3) were attached to the footbridge on the both sides, in the middle and in the third of the span (see Fig. 4).

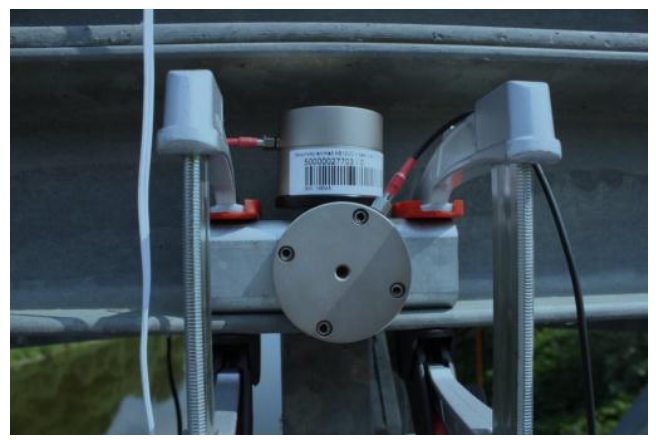

Fig. 3. Acceleration sensors.

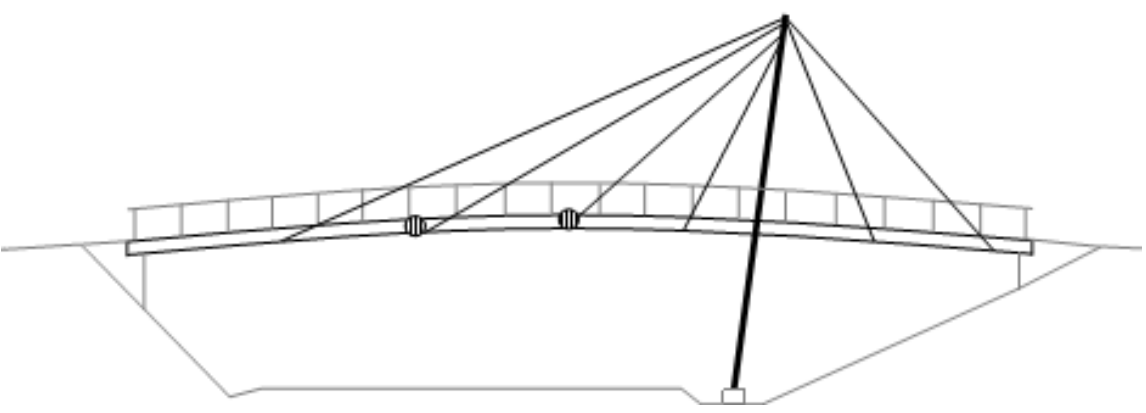

Fig. 4. Chart placement of sensors.

\subsection{Measurement data}

According to ČSN 736209 include determination of the natural frequencies of oscillation of the construction, which were evaluated from measured data (sample is in fig. 5) for each of the excitation load. Dominant frequencies were counted using specific load model because of suspension construction on the ropes.

As the most significant measured (excitation) natural frequency in vertical direction were evaluated these values: $2.5 \mathrm{~Hz} ; 2.8 \mathrm{~Hz} ; 5.1 \mathrm{~Hz} ; 7.5 \mathrm{~Hz}$.

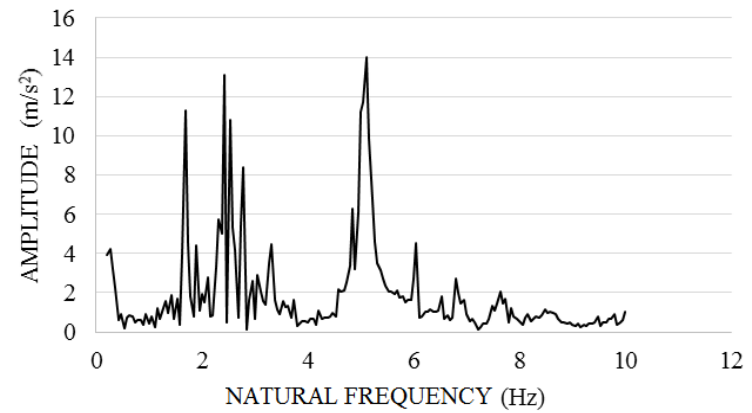

Fig. 5. One of records the measured data. 


\subsection{Evaluation of dynamical load test}

Due the fact that the measured values of natural frequency were higher than $5 \mathrm{~Hz}$, it was necessary to perform the analysis of another dynamic parameters which are values of acceleration. The most unfavourable acceleration values are presented in Table 1.

Table 1. Amplitudes of acceleration obtained for each state.

\begin{tabular}{|c|c|c|c|}
\hline \multirow{2}{*}{ load models } & amplitude & $\begin{array}{c}\text { maximum } \\
\text { acceleration }\end{array}$ & $\begin{array}{c}\text { effective } \\
\text { acceleration }\end{array}$ \\
\cline { 2 - 4 } & \multicolumn{3}{|c|}{$\left[\mathrm{m} / \mathrm{s}^{2}\right]$} \\
\hline walking one person by frequency $1 \mathrm{~Hz}$ & 1.0228 & 0.59 & 0.4172 \\
\hline walking group of persons by frequency $2 \mathrm{~Hz}$ & 1.7224 & 1.17 & 0.8273 \\
\hline trot group of persons & 1.2324 & 0.95 & 0.6717 \\
\hline run group of persons & 3.1482 & 1.95 & 1.3788 \\
\hline
\end{tabular}

The limits of permissible effective value of acceleration according to ČSN 736209 is shown in Fig. 6. The values listed in Figure 6 correspond to the maximum amplitude acceleration acquired in dynamic load test. The response to excitation of the bridge structure is at maximum amplitude of the range $1.6 \mathrm{~Hz}$ to $2.1 \mathrm{~Hz}$.

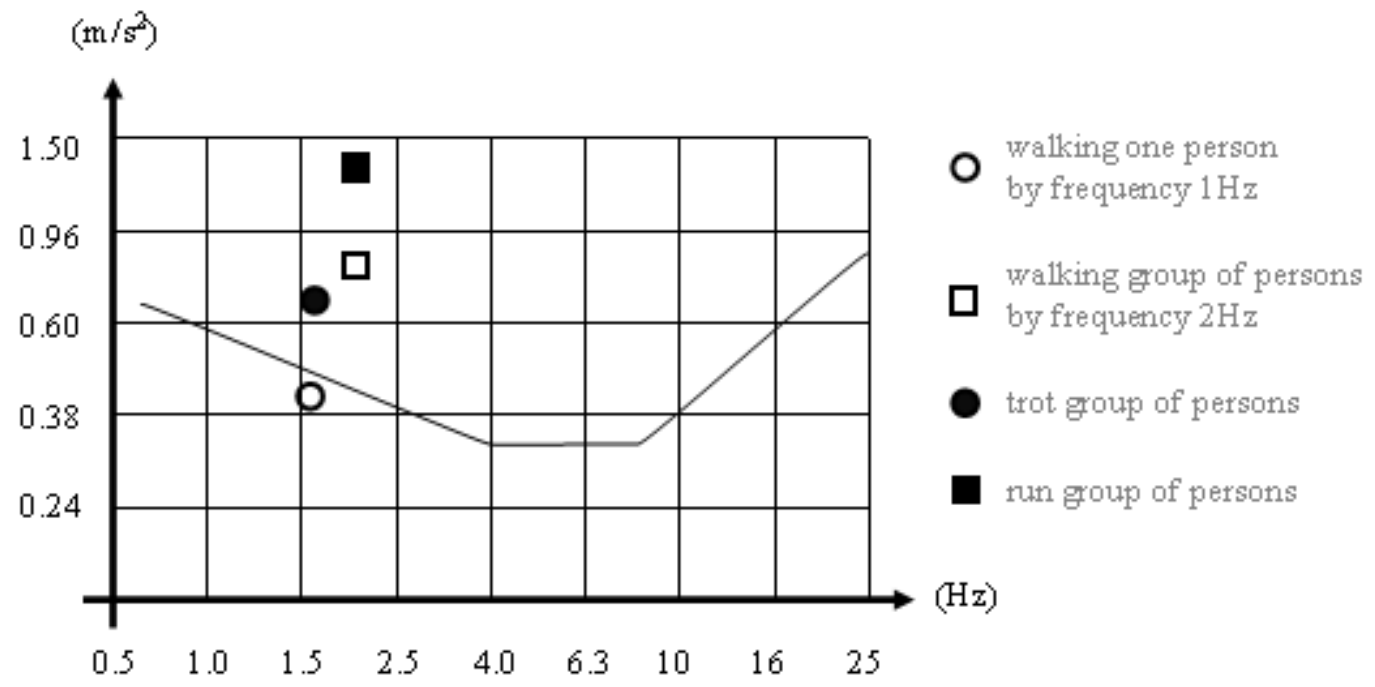

Fig. 6. The results of dynamic tests.

To meet the limit the effective acceleration value shell be below the curve shown in Fig. 6. It is obvious that requirements were not satisfied. 


\section{Conclusion}

The bridge construction put into service must meet the criteria both in terms of load carrying capacity but also in terms of usability perspective, which includes vibration limits on the structure. To determine the models of dynamic characteristic, it is necessary to perform the prescribed dynamic tests. On the basis of dynamic tests, it is possible to propose appropriate measures to correct the behaviour of the structure.

On the observed footbridge, the dynamic load test was conducted. Due the fact that the limits of vibration were exceeded, there was made analysis of effective acceleration value. This analysis also proved the exceeding of the limits. The results proved that is necessary to install vibration dampers.

The project was supported by the Student Grant Competition VSB - TUO. The project registration number is SP2016/136.

\section{References}

1. R. Fojtík, A. Lokaj, D. Mareček, Diagnostics of footbridge over the Jizera river in Benešov. Trans Tech Publication Ltd, 752-753, 124-131 (2015)

2. V. Cecháková, M. Rosmanit, R. Fojtík, FEM modeling and experimental tests of timber bridge structure. Procederia Engineering, 40, 79-84, (2012), DOI 10.1016/ j.proeng.2012.07.059

3. R. Fojtík, T. Novotný, I. Skotnicová, M. Stolárik, N. Zdražilová, M. Pinkak, Dynamic experimental analysis of steel bridge. Advanced Material Research, 1020, 215-220, (2014), DOI 10.402/www.scientific.net/ARM.1020.215

4. J. Rumlová, R. Fojtík, The Timber Tie Beam: The Analysis of Spatial Framework Joint, Procedia Engineering, 114, 132-139, (2015), DOI 10.1016/j.proeng.2015.08.051

5. V. Vašková, R. Fojtík, D. Pustka, Monitoring and failures of footbridges made from glued laminated wood. Procedia Engineering, 142, 87-91, (2016), DOI: 10.1016/ j.proeng.2016.02.017

6. A. Lokaj, J. Vičan, J. Gocál, Theoretical and experimental analysis of timber structure behavior. Building Materials 7, (2010) 